\title{
Erratum to: A new dynamic six degrees of freedom disc-loading simulator allows to provoke disc damage and herniation
}

\author{
Hans-Joachim Wilke ${ }^{1}$ Annette Kienle ${ }^{2}$ - Sebastian Maile ${ }^{1}$ - Volker Rasche ${ }^{3,4}$. \\ Nikolaus Berger-Roscher ${ }^{1}$
}

Published online: 9 May 2017

(c) Springer-Verlag Berlin Heidelberg 2017

\section{Erratum to: Eur Spine J (2016) 25:1363-1372 DOI 10.1007/s00586-016-4416-5}

The article "A new dynamic six degrees of freedom discloading simulator allows to provoke disc damage and herniation", written by Wilke et al. was originally published Online First without open access. After publication in volume 25, issue 5, page 1363-1372, the author decided to opt for Open Choice and to make the article an open access publication. Therefore, the copyright of the article has been changed to (C) The Author(s) [2016] and the article is forthwith distributed under the terms of the Creative Commons Attribution 4.0 International License (http:// creativecommons.org/licenses/by/4.0/), which permits use, duplication, adaptation, distribution and reproduction in any medium or format, as long as you give appropriate credit to the original author(s) and the source, provide a link to the Creative Commons license, and indicate if changes were made.

The online version of the original article can be found under doi:10.1007/s00586-016-4416-5.

Hans-Joachim Wilke

hans-joachim.wilke@uni-ulm.de

Annette Kienle

annette.kettler@spineserv.de

Sebastian Maile

sebastian.maile@gmx.de

Volker Rasche

volker.rasche@uni-ulm.de

Nikolaus Berger-Roscher

nikolaus.berger-roscher@uni-ulm.de

1 Institute of Orthopedic Research and Biomechanics, Trauma Research Center Ulm, Helmholtzstraße 14, 89081 Ulm, Germany

2 SpineServ GmbH and Co. KG, Söflinger Straße 100, 89077 Ulm, Germany

3 Department of Internal Medicine II, University Hospital Ulm, Albert-Einstein-Allee 23, 89081 Ulm, Germany

4 Small Animal MRI, Medical Faculty, Ulm University, Albert-Einstein-Allee 11, 89081 Ulm, Germany 